\title{
Pressure drop at low Reynolds numbers in woven-spacer-filled channels for membrane processes: CFD prediction and experimental validation
}

\author{
L. Gurreri, A. Tamburini*, A. Cipollina, G. Micale, M. Ciofalo \\ Dipartimento di Ingegneria Chimica, Gestionale, Informatica, Meccanica (DICGIM), Università di Palermo (UNIPA) - viale delle \\ Scienze Ed.6, 90128 Palermo, Italy, e-mail: luigi.gurreri@unipa.it (L. Gurreri), alessandro.tamburini@unipa.it (A. Tamburini), \\ andrea.cipollina@unipa.it (A. Cipollina),giorgiod.maria.micale@unipa.it (G. Micale),michele.ciofalo@unipa.it (M. Ciafalo)
}

Received 12 October 2015; accepted 2 May 2016

\begin{abstract}
A B S T R A C T
The energy consumption due to pumping power is a crucial issue in membrane processes. Spacers provide mechanical stability and promote mixing, yet increasing pressure drop. Woven spacers and their behaviour at low Reynolds numbers are less studied in the literature. Nevertheless, they are typical of some membrane technologies, as reverse electrodialysis (RED). RED is a promising technology for electric power generation by the chemical potential difference of two salt solutions within a stack equipped by selective ion-exchange membranes. The mechanical energy required for pumping the feed solutions, can dramatically reduce the net power output. In this work computational fluid dynamics (CFD) simulations of spacer-filled channels at low Reynolds numbers were carried out in parallel with an experimental campaign focused on the collection of data for model validation. Woven spacers 280-480 $\mu \mathrm{m}$ thick were investigated at the flow rates typical of RED channels. The construction of the computational domain was based on measurements made by optical microscopy and micrometer. Fully developed flow conditions were assumed, thus, periodic boundary conditions were adopted (unit cell approach). The experiments were carried out in a flow cell with one channel. Pressure drops were measured with and without the spacer, in order to quantify the effect of inlet-outlet channel and identify the distributed pressure drops due to the woven nets. Experimental results showed that the distributed pressure drop along the spacer-filled channel for the cases investigated is around $40 \%$ of the overall pressure loss. The significant contribution of the manifolds is due to the relatively high velocity of the fluid entering and leaving the channel in radial direction in the inlet and outlet holes, as in the RED stacks commonly used. However, an improved geometry of the distribution and collection system can easily result in a significant reduction of hydraulic loss in this part of the stack. Therefore, the optimization of the spacer geometry is crucial. In this regard, a good agreement between CFD results and experimental data on hydraulic loss along the channel was found, thus confirming that a simple CFD model (as the one presented in this work) can be a powerful and cheap tool, able to efficiently evaluate the pressure drops within spacer-filled channels of any customised geometry.
\end{abstract}

Keywords: Woven spacer; Pressure drop; Low Reynolds numbers; CFD; Reverse electrodialysis; Membrane processes

\section{Introduction}

Fig. 1 shows some kinds of net spacers commercially available and commonly employed in many membrane

*Corresponding author. separation processes. Spacers promote mixing but increase pressure drop and thus mechanical energy losses [1-7]. Therefore, a compromise must be sought. In particular, in processes having as their output electric energy (RED, PRO) pumping losses act immediately as a direct reduction of the net power output. In other processes, e.g. those

Presented at EuroMed 2015: Desalination for Clean Water and Energy Palermo, Italy, 10-14 May 2015.

Organized by the European Desalination Society. 
a)

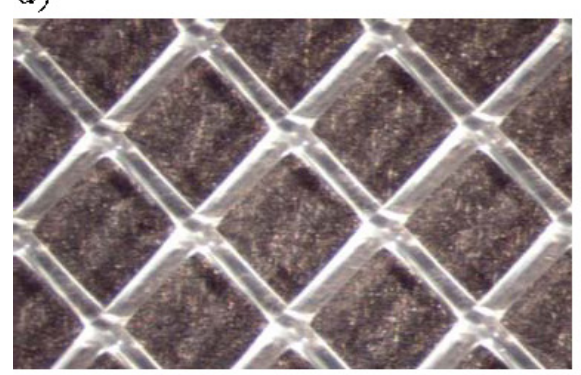

d)

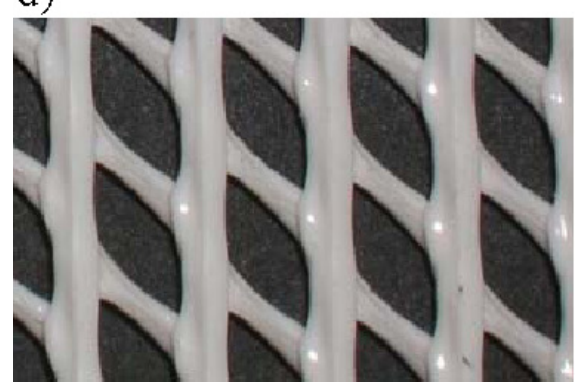

b)

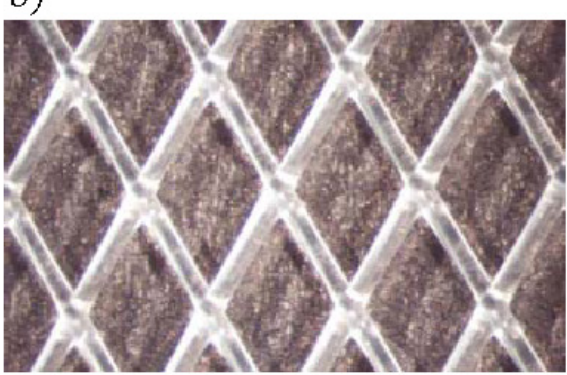

e)
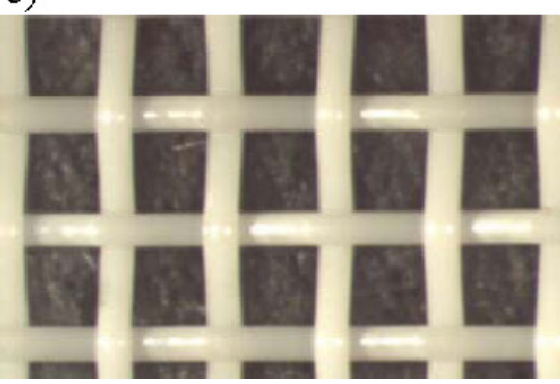

c)

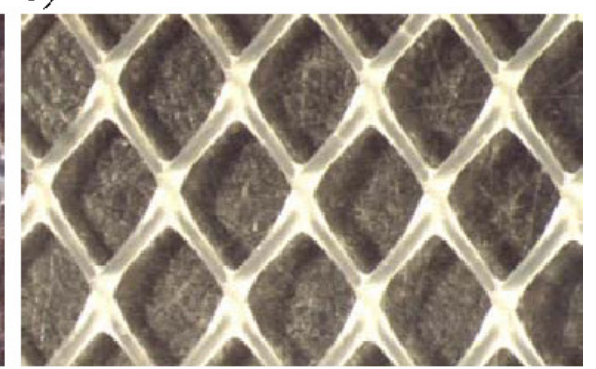

f)

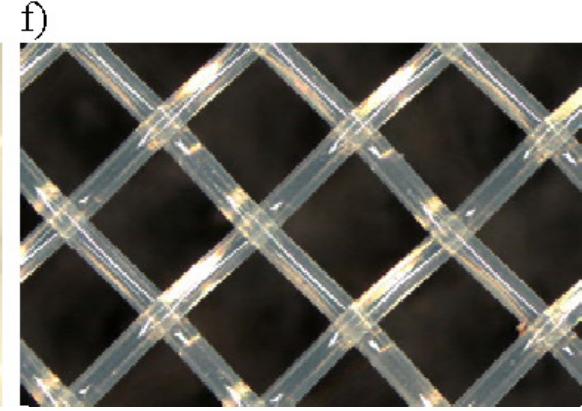

Fig. 1. Different kind of net spacers: a) with overlapped crossing filaments at $90^{\circ}, \mathrm{b}$ ) with overlapped crossing filaments at $60 / 120^{\circ}$, c) extruded with crossing filaments at $60 / 120^{\circ}$, d) extruded with irregular shape of filaments, e) with woven crossing filaments at $90^{\circ}$, f) with woven crossing filaments at $90^{\circ}$, but coarser than e).

having as their product fresh water (UF, NF, RO, MD, ED), the relative importance of pumping losses depends on the relative cost of electric energy and product. Whatever the specific membrane process considered, an accurate estimate of pumping losses is a crucial step in the overall design and economic assessment of a plant. Depending on the different membrane process under consideration, different Reynolds numbers are typically involved. The present paper focuses on pressure drops estimates at low Reynolds numbers typical of $\operatorname{RED}(\operatorname{Re} \approx 1-25)$ for the case of woven spacers.

Among membrane processes, reverse electrodialysis (RED) is a very promising technology that converts the salinity gradient energy directly into electric energy. With respect to capacitive mixing and mixing entropy battery, RED exhibits higher power densities [8]. In RED, two salt solutions flow in alternating channels, separated by an alternated series of anion and cation exchange membranes. The chemical potential difference between the two solutions triggers a transport across the membranes that allow a selective passage of the ions from the concentrated channels towards the dilute ones. At the electrodes, the ionic transport is converted by redox reactions into a current of electrons supplying an external load [9-11].

Pressure drops depend on the stack geometry, the feeds flow rate and the feeds features. These factors affect also other aspects as the Ohmic resistances and the nonOhmic resistances (due to the concentration polarization and the streamwise change of the bulk concentration) which reduce the actual driving force [7,12-14]. Therefore, in the optimization of the stack and of the operating conditions one has to account for the combined effects of several factors on various aspects [15-17]. However, among these, pressure drops and consequent power consumption might have the major impact on the process efficiency
$[7,11,13,14,18]$ especially when highly concentrated solutions are employed [19].

The total pressure drop along the stack from inlet to outlet includes various contributions. In general, it can be divided in: (i) the pressure drop in the distribution/collection system and (ii) the pressure drop along the channels [18].

Very thin channels are used in RED stacks. The channel thickness is usually $\sim 100-500 \mu \mathrm{m}$, the channel length ranges from $10 \mathrm{~cm}$ (laboratory scale) to $\sim 40 \mathrm{~cm}$ (prototype scale); the typical linear flow velocities at which the maximum net power is obtained are around $1 \mathrm{~cm} \mathrm{~s}^{-1}$, corresponding to very low Reynolds numbers (lower than 5) [7,10$14,18,20,21]$. Therefore, the fluid flow regime is perfectly steady. Net spacers are usually adopted as mechanical support within the channels and as mixing promoters (in order to reduce concentration polarization). On the other hand, a channel created by a non-conducting spacer exhibits higher Ohmic resistances compared to the spacer-less channel $[7,10,12,22,23]$ and higher pressure drop. Experimental data highlight that the hydraulic loss per unit length is much higher compared to that one in an empty channel of infinite streamwise and spanwise extent, with increments of one/ two orders of magnitude $[6,7,13,14,17,24]$.

In the most common kind of stack geometry, cylindrical ducts created by holes (in spacers, gaskets and membranes) generate high variations of cross-section and thus of fluid velocity at the inlet/outlet zones of the channel (e.g. Fig. 2 of [13]). Therefore, pressure drop due to the manifolds may be high $[6,11,13,14,18,24,25]$. Nevertheless, an improved geometry of the distribution system can dramatically reduce this contribution, while the increment of pressure drop along the channel due to a spacer remains quite higher with respect to the empty channel, as clearly shown in [14], and the spacer features have a decisive impact on pressure drop $[7,14,20]$. 


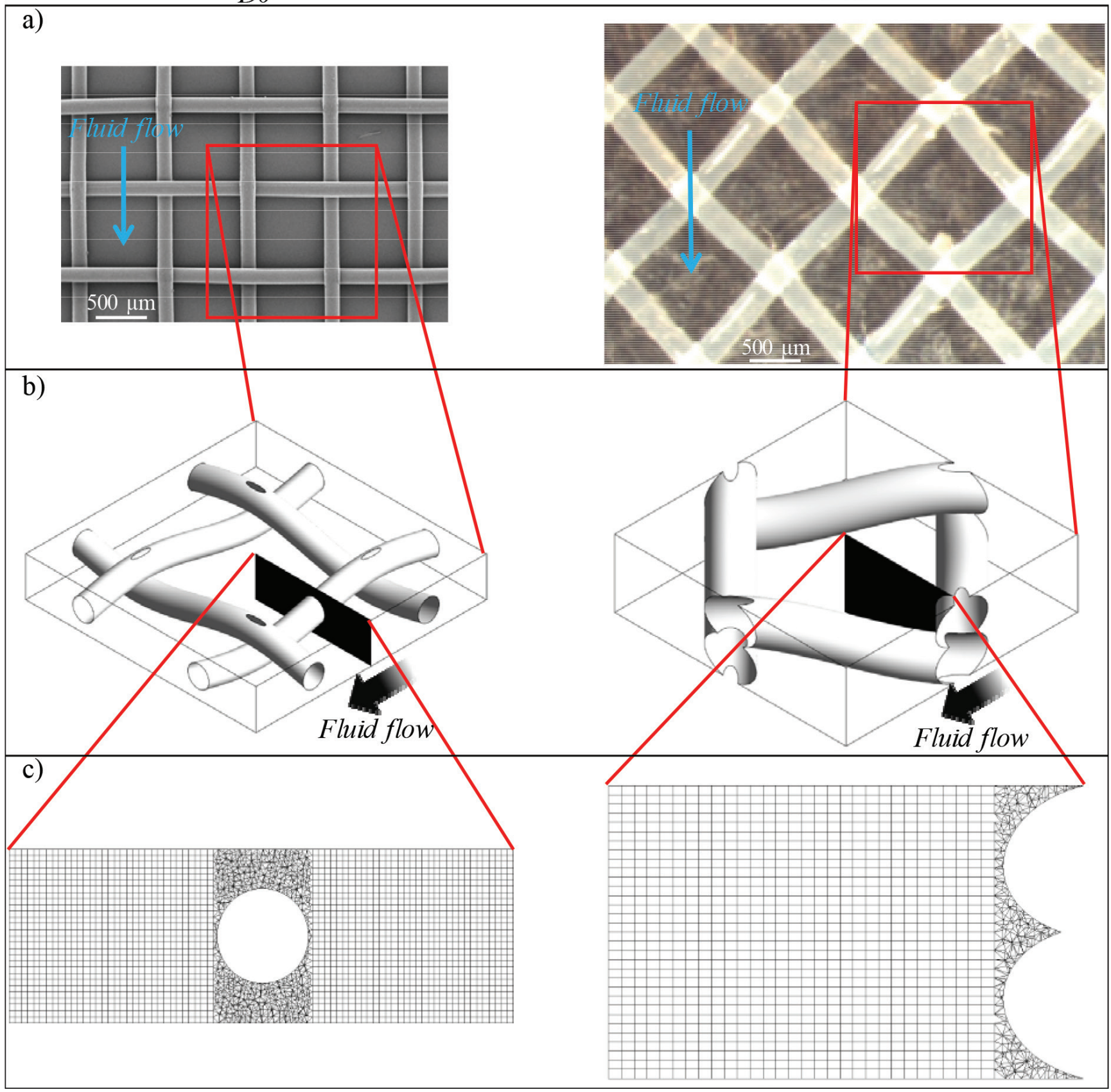

Fig. 2. Spacers investigated. Left: D0; right: F45. (a) Microscope photos; (b) Unit cell geometry; (c) details of the mesh over one half of a cross section of the unit cell.

Therefore, the assessment of the pressure drop within the spacer-filled channel is a prominent issue for the stack optimization. In this regard, Computational fluid dynamics (CFD) has been successfully adopted in many literature studies on spacer-filled channels for membrane separation processes $[26,27]$. CFD, once validated with experimental or analytical data, offers several advantages over the experimental investigation, including the possibility to test many cases with cost effective results, the effectiveness as predictive tool and the detailed analysis at small scale.
In the past, the available hardware permitted to carry out 2D simulations in acceptable times. For example, Schwinge et al. [28] simulated flow dynamics inside 2D channels with circular spacer filaments of different configurations. In the last decade, the technological advancement has allowed 3D simulations with a more and more accurate spatial resolution. Many CFD studies were performed by simulating the periodic domain of the spacer-filled channel (for more details, see section 3.1). Both commercially available spacers [29] and non-commercially available spacers 
[30-35] were simulated. In these works, various geometrical parameters of spacers made by overlapping two series of cylindrical filaments were investigated: angle between crossing filaments, filament spacing, filament size, and flow attack angle. Also multi-layer and non-conventional (different filament shapes) spacers were studied $[33,36-38]$. However, it appears clear that the literature is almost void of results on pressure drop in woven spacer-filled channels. To the authors knowledge, the only examples are represented by our previous publications $[19,39]$. On the other hand, the experimental campaigns for RED applications have been commonly carried out with woven spacers $[7,12,18]$. These spacers allow a mixing enhancement, at equal pumping power consumption, with respect to the spacers made by overlapped filaments [39].

It should be also stressed that in the literature CFD studies cited above, the Reynolds numbers considered are relatively high $(>50)$, i.e. in the range of interest for many membrane processes, but not for RED applications. Only few works have been devoted to the CFD simulation in the low Reynolds numbers range typical for RED. Beyond the works of our research group [19,39-42], the only example is the work of Pawlowski et al. [43].

A comparison of CFD results for woven spacers, non-woven spacers and profiled-membranes at low Reynolds numbers, including both pressure drop and mass transfer, was conducted in our previous papers $[19,39,40]$. The main purpose and the novelty of the present work is in the direct comparison of CFD results and experimental data on pressure drop along the channel, in order to validate the model predictions. In particular, woven spacers have been investigated by (i) the CFD model based on the Unit Cell approach already presented in previous works $[19,39,40]$, and (ii) experimental data purposely collected by tests in a flow cell. Of course, the choice of the best channel configuration cannot be done by considering only pressure drop, but requires a comparison of electric power output, which in its turn depends also on other aspects, as mass transfer coefficients, shadow effect, ohmic resistance, fouling, which are beyond the scope of the present work.

\section{Experimental section}

\subsection{Spacers under investigation}

The pressure drop distributed along the channel was investigated for two commercial spacers by experimental tests and CFD simulations. Both the spacers are constituted of woven filaments $90^{\circ}$ angled with circular cross-section and equal spacing and size for the two layers (Fig. 2a). One spacer was supplied by Deukum (thickness of $280 \mu \mathrm{m}$ ) and was already investigated by our research group in a previous work [19]. Another spacer was supplied by Fumatech (thickness of $480 \mu \mathrm{m}$ ). For convenience, hereafter the test cases studied will be indicated by a letter followed by a number; the letter identifies the spacer (D for Deukum, F for Fumatech) while the number specifies the flow attack angle.

The spacer features were measured by optical microscopy and micrometer aiming at building a computational geometry as much similar as possible to the real one. In this regard, the measurements show that the spacer filaments are compressed, with non-circular cross-section, due to the manufacturing. This feature was taken into account as follows. For simplicity, (i) the filament was assumed with circular cross-section with diameter equal to that measured via optical microscopy photographs, and (ii) the difference between twice the filament diameter and the spacer thickness (measured by the micrometer) was attributed $70 \%$ to the overlap region of the filaments and $30 \%$ to the filament-wall contacts [19]. All spacer features are summarized in Table 1, showing also the angle between the main flow direction and the filaments. Notably, the spacers are provided with an integrated gasket that imposes the orientation of the filaments with respect to the main flow direction.

\subsection{Flow cell}

The experimental apparatus consists of a flow cell in the conventional plate-and-frame geometry (Fig. 3). The spacer was interposed between two rigid transparent plates in Plexiglas, so that eventual air bubbles could be easily detected. The solution was fed and discharged by three inlet/outlet holes. The spacers were provided with integrated gasket and inlet/outlet holes. Threaded rods and nuts were used in order to fix the device. The applied tightening force was selected once for all by trial and error so that (i) hydraulic seal was obtained (no solution leakage) and, at the same time, (ii) the walls touched the spacer filaments with only a moderate amount of deformation, as similar as possible to that existing in a real RED stack. A torque wrench was used to ensure that the same amount of tightening was applied in all subsequent tests.

\subsection{Feed solutions}

The experiments were performed with two feed solutions at $25^{\circ} \mathrm{C}$ : (i) distilled water and (ii) a $5 \mathrm{M} \mathrm{NaCl}$ solution (brine), which was filtered by a $20 \mu \mathrm{m}$ cartridge filter. The physical properties of the feed solutions are summarized in Table $2[44,45]$. Testing two different solutions

Table 1

Geometric features of the spacers investigated and angle between the flow direction and a filament

\begin{tabular}{lllllllll}
\hline Configuration & $\begin{array}{l}\text { Supplier/ } \\
\text { manufacturer }\end{array}$ & $\begin{array}{l}\text { Filament } \\
\text { arrangement }\end{array}$ & $\begin{array}{l}\text { Thickness } \\
h[\mu \mathrm{m}]\end{array}$ & $\begin{array}{l}\text { Filament } \\
\text { diameter }[\mu \mathrm{m}]\end{array}$ & $\begin{array}{l}\text { Pitch }(\mathrm{mesh} \\
\text { length) }[\mu \mathrm{m}]\end{array}$ & $\begin{array}{l}\text { Volume } \\
\text { porosity } \\
{[-]}\end{array}$ & $\begin{array}{l}\text { Angle } \\
\text { between } \\
\text { filaments }\left[{ }^{\circ}\right]\end{array}$ & $\begin{array}{l}\text { Angle between } \\
\text { flow direction } \\
\text { and a filament }\left[{ }^{\circ}\right]\end{array}$ \\
\hline D0 & Deukum & Woven & 280 & 148 & 809 & 0.85 & 90 & 0 \\
F45 & Fumatech & Woven & 480 & 260 & 1160 & 0.81 & 90 & 45 \\
\hline
\end{tabular}




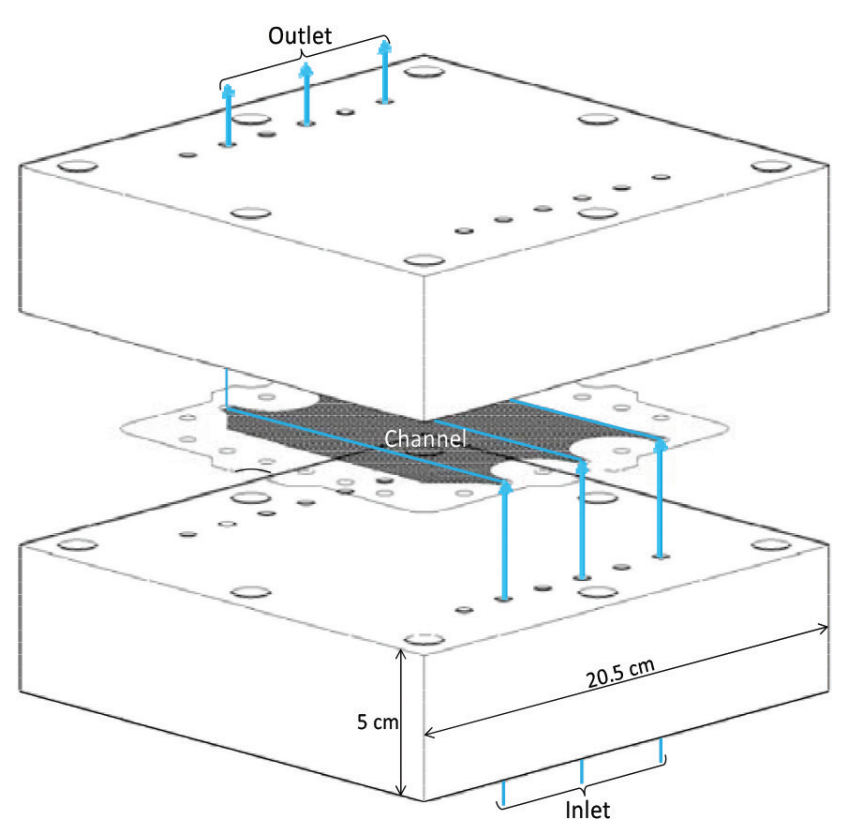

Fig. 3. The flow cell adopted for the experimental measurements of pressure drops.

Table 2

Physical properties of the two solutions tested: $5 \mathrm{M} \mathrm{NaCl}$ aqueous solution, and distilled water at $25^{\circ} \mathrm{C}$

\begin{tabular}{llll}
\hline Solution & $\begin{array}{l}\text { Concentration } \\
{\left[\mathrm{mol} \mathrm{l}^{-1}\right]}\end{array}$ & $\begin{array}{l}\text { Density } \\
{\left[\mathrm{kg} \mathrm{m}^{-3}\right]}\end{array}$ & $\begin{array}{l}\text { Viscosity } \\
{[\mathrm{Pa} \mathrm{s}]}\end{array}$ \\
\hline Brine & 5.0 & 1182.8 & $1.659 \cdot 10^{-3}$ \\
Distilled water & - & 997.0 & $8.899 \cdot 10^{-4}$ \\
\hline
\end{tabular}

can be useful in order to show the soundness of method and equipment, once data are made dimensionless. Also, the brine solution was useful to extend investigations to lower Reynolds numbers without losing accuracy. Finally, the availability of more data can be welcome for the validation.

During the tests, the feed solution was pumped through the flow cell by a peristaltic pump at flow rates ranging from 0.87 to $63 \mathrm{ml} \mathrm{min}{ }^{-1}$. The corresponding highest Reynolds number was $\sim 24$. Typically, 9-10 different flow rates were investigated for each spacer configuration. The solution was fed from below, and, during the filling of the flow cell, trapped air bubbles were carefully removed. Fig. 4 schematically shows the whole experimental test rig.

\subsection{Measurements and data acquisition}

The pressure downstream of the pump was measured by a pressure transducer (Sensortechnics) that generates an electric signal from 0 to $10 \mathrm{~V}$, corresponding to the pressure range $0-2$ barg, and is connected to a DC power supply. The sensitivity of the instrument is $10 \mathrm{~Pa}$, and its accuracy depends on the calibration. This was performed by letting

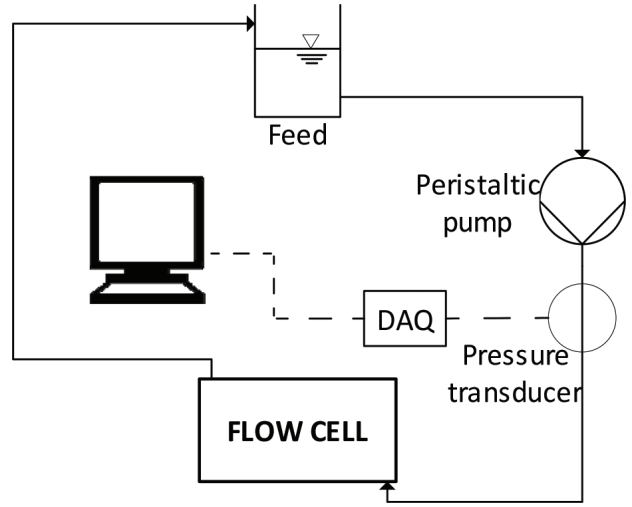

Fig. 4. Sketch of the experimental test rig for the pressure drop measurements.

the hydrostatic head of a water column to vary. The pressure transducer was provided with a data logger (National Instruments DAQ NI USB 6210) for detecting and recording measurements continuously. Data were acquired and managed in a computer by the software Lab VIEW.

\subsection{Experimental procedure}

Pressure drops were measured with and without the spacer, in order to quantify the effect of inlet-outlet channel and identify the distributed pressure drops due to the woven nets. Due to the small size of the channel and to the flow cell geometrical characteristics, it was not possible to "directly" measure the pressure losses along the channel caused by the spacer: only in-out pressure measurements were possible. Therefore, in order to isolate the pressure drops along the spacer-filled channel, an ad-hoc procedure was purposely set up based on the employment of two different channel configurations for the experiments (shown in Fig. 5):

(a) a flow cell with a full spacer;

(b) a flow cell with a spacer deprived of its central area $\left(10 \times 10 \mathrm{~cm}^{2}\right)$ which was cut thus resulting in a channel unprovided with a spacer (except that the areas near the inlet and the outlet).

By means of these configurations, two different $\Delta p$ were measured (during two separate experiments):

- $\Delta p_{\text {over }}$ including external loss, distributed spacer filled-channel loss and in-out loss;

- $\Delta p_{\text {empty }}$ including external loss, distributed empty channel loss and in-out loss.

The distributed pressure drops per unit length within the spacer-filled channel were obtained as

$$
\frac{\Delta p_{\text {spacer }}}{\Delta z}=\frac{\Delta p_{\text {over }}-\left(\Delta p_{\text {empty }}-\Delta p_{H P}\right)}{\Delta z}
$$

where $\Delta p_{H P}$ is the theoretical distributed loss in a corresponding spacer-less channel of infinite spanwise and 

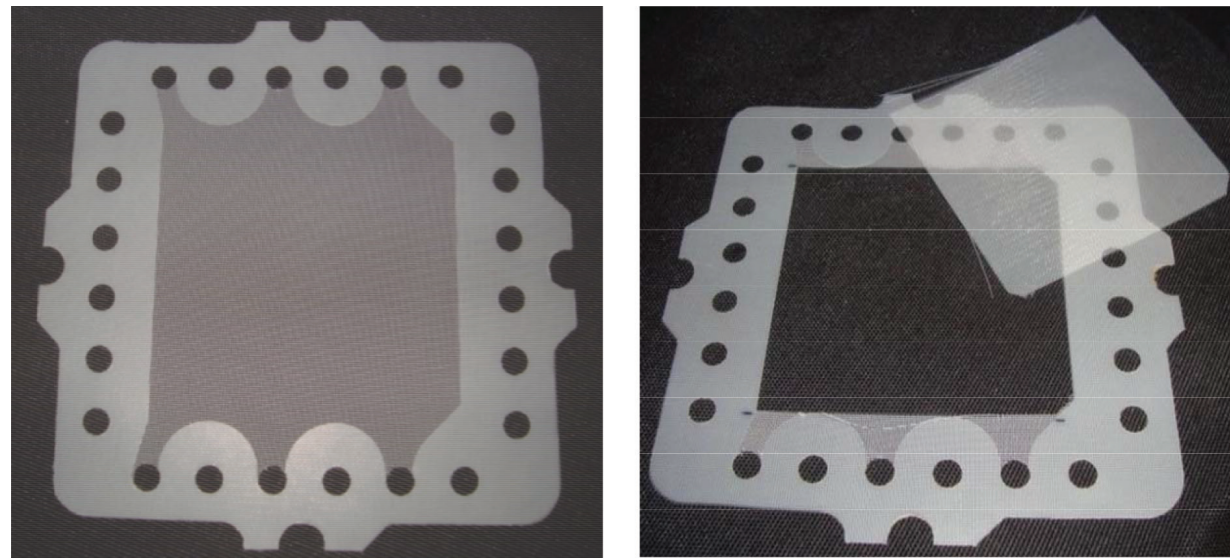

Fig. 5. Full spacer (left) and a spacer deprived of its central area (right).

stream wise extent, calculated by means of the Hagen-Poiseuille equation

$\frac{\Delta p_{H P}}{\Delta z}=\frac{12 \mu Q_{v}}{L h^{3}}$

where $\mu$ is dynamic viscosity, $Q_{v}$ is the volumetric flow rate, $L$ is channel width and $h$ is the channel thickness.

Note that the results on the overall pressure drop shown in the following take into account the height difference between the pressure transducer and outlet section in the flask: $\Delta p_{\text {over }}=p_{\text {transducer }}+\left(H_{\text {transducer }}-H_{\text {outlet section }}\right) \rho g$. Of course, for the calculation of the pressure drop within the spacer this correction was not needed, as it was obtained by the difference of two measurements of in-out pressure drops $\left(\Delta p_{\text {over }}\right.$ and $\left.\Delta p_{\text {empty }}\right)$.

All measurements were performed twice in order to verify the reproducibility: after testing a series of flow rates, the flow cell was opened and then assembled for testing again the same series of flow rates. Discrepancies always below $7 \%$ were found. The mean values of the measurements were calculated and are reported in the results and discussion section.

\section{CFD modelling}

\subsection{Unit cell approach}

For systems like a spacer-filled channel, in which geometrical periodicity exists and a considerable amount of flow mixing is achieved, the flow field is known to become fully developed after just a few unit cells [46,47]. On the other hand, even at very low Reynolds numbers, the flow patterns in these channels may be very complex and characterized by very small structures, thus requiring very fine meshes to be properly simulated. The Unit Cell approach is the generally adopted solution to reliably simulate these channels $[19,30,31,33-35,39,41,42,48-50]$. The Unit Cell represents the repeating unit of the whole periodic domain which is typically investigated in CFD studies. Thanks to the periodicity of the velocity field, the obtained results can be considered as representative of the whole domain. This approach allows computational requirements to be greatly reduced and flow features at the small scale to be accurately predicted. Fig. $2 \mathrm{~b}$ shows the unit cells adopted. Notably, the computational domains were created on the basis of the geometric features indicated in Table 1.

The governing equations for the stationary motion of a Newtonian incompressible fluid within a periodic domain are the following continuity and momentum transport (Navier-Stokes) equations:

$\vec{\nabla} \cdot \vec{u}=0$

$\rho \vec{u} \vec{\nabla} \cdot \vec{u}=-\vec{\nabla} \tilde{p}+\mu \nabla^{2} \vec{u}+K_{p} \vec{k}$

where $\vec{u}$ is velocity, $\rho$ is density, $\mu$ is dynamic viscosity, $\tilde{p}$ is the periodic component of pressure (whose spatial distribution repeats itself identically in each Unit Cell) and $K_{p}$ is a body force per unit volume representing the largescale gradient of the pressure that decreases linearly along the main flow direction (coincident with the $z$ axis in the present work) $[19,41]$. As expected, in the range of the flow rates investigated here, the flow regime was found to be steady in preliminarily performed transient simulations. The density was assumed to be constant (equal to those reported in Table 2) and buoyancy was neglected.

\subsection{Grid independence assessment}

As regards discretization, Unit Cells were meshed by multi-block hybrid grids mainly composed of hexahedral volumes. In particular, the regions near the wires were discretized with tetrahedrons, the remaining part of the domain was discretized with hexahedra (Fig. 2c), with a few pyramids and wedges at the interfaces between the two parts [19,39]. Grid independence was preliminarily addressed for the case of the highest pressure gradient imposed. For example, Fig. 6 shows how the results vary as the discretization degree increases; in particular, it shows the normalized velocity along the central line perpendicu- 

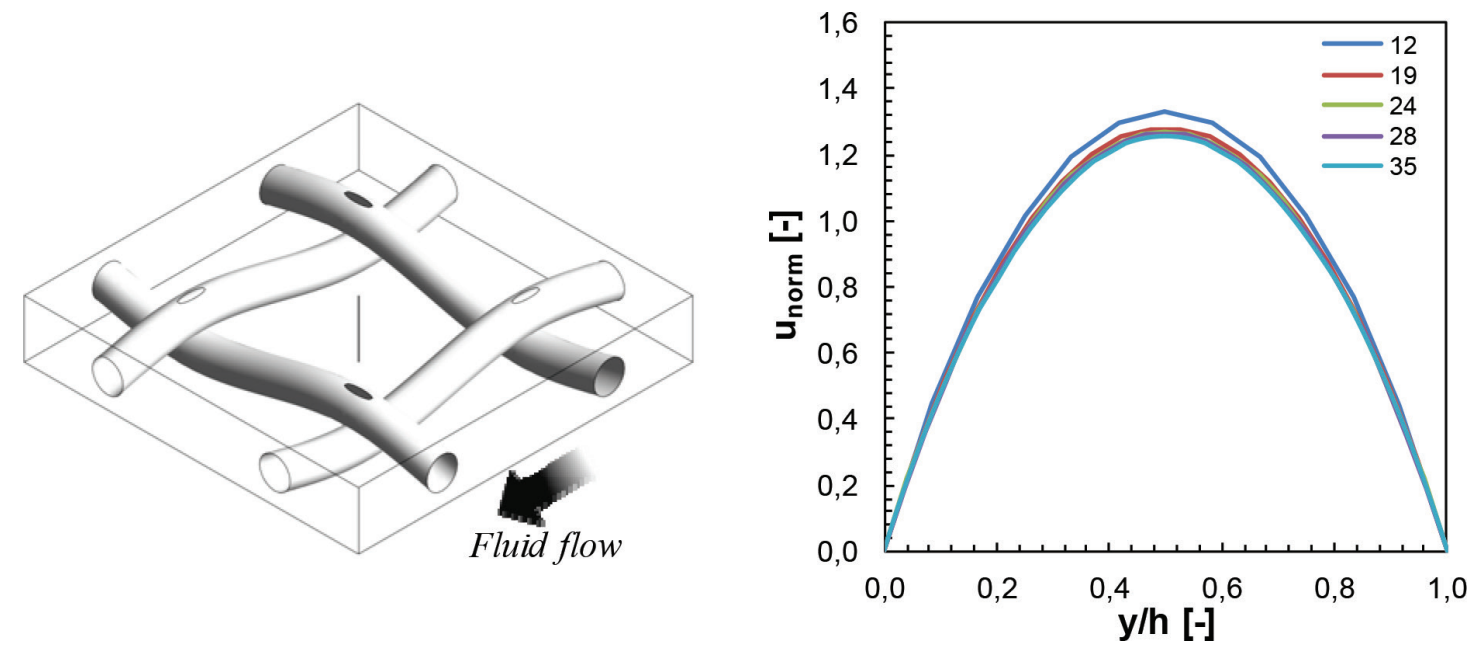

Fig. 6. Left: indication of the central monitoring line perpendicular to the walls. Right: normalized velocity along the monitoring line for the D0 spacer-filled channel as a function of the number of the finite volumes in height.

lar to the walls for the D0 spacer-filled channel as a function of the number of the finite volumes in height (note that the domain discretization degree is proportional to this number). According to these results, the grid chosen to carry out the subsequent simulations was with 28 volumes in height, which also allowed to obtain an average value of velocity along the main flow direction with a discrepancy of $1.6 \%$ with respect to the finest grid.

The features of the grids chosen via the grid dependence analysis for the two spacers and employed to run the various simulations are summarized in Table 3.

Note that the fineness of the grids decreases slightly as the pitch-to-height ratio increases (the pitch of the spacer is the normal distance between two subsequent filaments). However, for the case of the D0 spacer, the domain simulated is not the minimum repetitive unit, but a squared cell with side equal to two times the pitch which results into a correspondingly higher number of finite volumes.

Translational periodic boundary conditions were imposed at the lateral boundaries of the domain (fluid-fluid interfaces). In the Oxyz reference frame, the computational domains were oriented so that the main flow direction coincided with the $z$ axis. The body force per unit volume $K_{p}$ in Eq. (4) was set ranging from $\sim 800$ to $\sim 32700 \mathrm{~Pa} \mathrm{~m}^{-1}$. The corresponding highest Reynolds number was $\sim 24$. All the other boundaries (i.e. upper, lower and filament surface), consisting of the fluid-solid interfaces, were set as walls along with no-slip conditions. Notably, the slip length depends on

Table 3

Summary of the grids employed

\begin{tabular}{lllll}
\hline $\begin{array}{l}\text { Unit } \\
\text { cell }\end{array}$ & $\begin{array}{l}\text { Pitch/ } \\
\text { height } \\
{[-]}\end{array}$ & $\begin{array}{l}\text { Number } \\
\text { of finite } \\
\text { volumes in } \\
\text { height } h\end{array}$ & $\begin{array}{l}\text { Number } \\
\text { of finite } \\
\text { volumes }\end{array}$ & $\begin{array}{l}\text { \% of domain } \\
\text { volume } \\
\text { discretized with } \\
\text { hexahedra }\end{array}$ \\
\hline D0 & 2.89 & 28 & $\sim 1^{\prime} 600^{\prime} 000$ & 76.1 \\
F45 & 2.42 & 32 & $\sim 1^{\prime} 126^{\prime} 000$ & 71.4 \\
\hline
\end{tabular}

many physical parameters, as well as the wettability (and the surface energy) and could be high even for hydrophilic surfaces. In fact, there is a poor correlation between slip and contact angle [51]. Moreover, the same reference highlights that (i) the slip lengths reported experimentally span from molecular lengths up to hundreds of nanometers, and (ii) the impact of slip on systems with typical dimensions larger than tens of microns will therefore likely be limited. Finally, no specific data on the real slip condition on polymeric surfaces are available. For these reasons, we applied the no slip condition on the walls, as in all the CFD studies on spacers cited in this work.

\subsection{Numerical methods}

All simulations were conducted by the ANSYS-CFX14 ${ }^{\circledR}$ code [52]. It is one of the latest development of a long suite of finite volume CFD codes which have successfully been applied through the years by the authors' research group to a variety of fluid dynamics problems including mixing in spacer-filled channels.

In its current version, the code uses a finite volume approach and a co-located (non-staggered) grid layout, such that the control volumes are identical for all transport equations. Since native co-located methods lead to a decoupled (checkerboard) pressure field [53], the Rhie and Chow [54] discretization method for the mass flows is used here to avoid this decoupling. Solution fields and other properties are stored at the mesh nodes (vertices of the control volumes); finite element-type shape functions are used to approximate the solution field or the solution gradients at integration points, as required by the evaluation of the various terms of the discretized transport equations.

The code uses a coupled solver, in which the hydrodynamic equations for the three velocity components and pressure are treated as a single large system. A multi-grid (MG) accelerated incomplete lower upper (ILU) factorization technique is adopted for solving the discrete system of linearized equations. The multi-grid process involves 
carrying out early iterations on a fine mesh and later iterations on progressively coarser virtual ones; the results are then transferred back from the coarsest mesh to the original fine mesh. To prevent the need to explicitly build a series of different mesh spacings, ANSYS CFX uses an additive correction algebraic multigrid approach [55], in which the discretization of the non-linear equations is performed (only once) for the finest mesh, while the system of discrete equations for each coarser mesh is formed by summing the finer mesh equations.

In the present, steady-state, simulations, diffusive terms were interpolated by the central scheme, while advection terms were interpolated by the "High Resolution" scheme, which is a hybrid first-second order blended upwind scheme suitable for general and unstructured grids [56]. In the worst case (geometry D0 at $\mathrm{Re} \approx 20$ ) the cell Péclet number $w \Delta z / v$, which is the crucial parameter to assess numerical viscosity effects, is of the order of $0.3<<2$. Therefore, the high resolution scheme behaves to all practical purposes as the central scheme and numerical viscosity effects are negligible.

The simulations were performed by an octa-core workstation with $2.6 \mathrm{GHz}$ CPU and 64 GB RAM.

\section{Results and discussion}

Fig. 7 reports experimental results relevant to $\Delta p_{\text {over }}$ and $\Delta p_{\text {emptty }}$ along with the calculated values of $\Delta p_{H P}$ and $\Delta p_{\text {spacer }}$ for the case of distilled water as feed solution. $\Delta p_{\text {spacer }}$ data are found $31 \%$ and $53 \%$ of the $\Delta p_{\text {over }}$ for the cases of the D0 and F45 spacers respectively. The manifolds are different for different spacer configurations, because they must fit to different channel thickness. The ratio of channel to total pressure drop changes from spacer to spacer because the hydraulic resistance of different spacers and that of the associated manifolds $\left(\approx \Delta p_{\text {empty }}-\Delta p_{H P}\right)$ do not change proportionally.

These results demonstrate that a significant contribution to the pressure drop can be attributed to the manifolds when the conventional stack geometry is used; in fact, these are responsible of high velocities of the fluid entering/

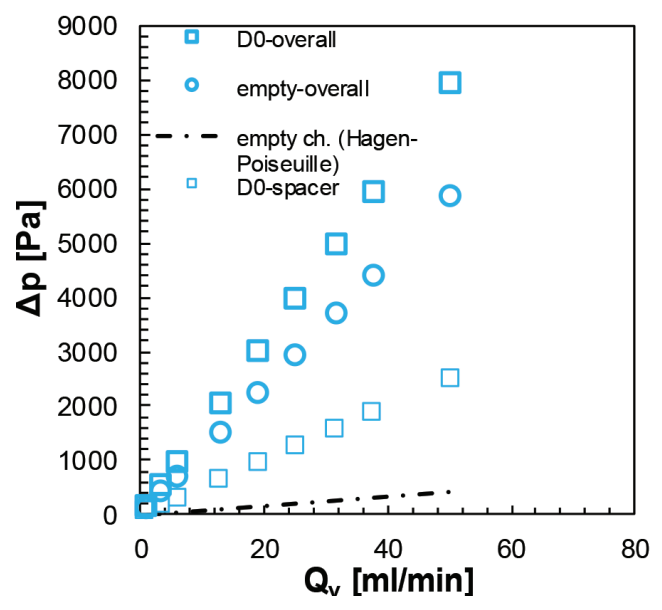

leaving the channel in radial direction at the inlet/outlet holes. On the other hand, the pressure drop is significantly reduced in a stack designed with wide and sufficiently thick manifolds, as shown by Vermaas et al. [14]. Moreover, in a previous work published by our research group [48] CFD simulations were performed on a simplified ideal planar hydraulic circuit of a 50-channel stack: rectangular manifolds being wide as the channels were devised, and such configuration was proved to be able to reduce significantly the concentrated hydraulic losses when the distributor thickness is sufficiently larger than the channels one.

Fig. 8 shows the comparison between experimental data and CFD predictions concerning the distributed pressure drops within the spacer-filled channel $\left(\Delta p_{\text {spacer }}\right)$, for two spacers (D0 and F45) and two different feed solutions (5 M brine and distilled water). Both the experimental and the predicted trends are linear: only the points at the largest flow rate exhibit a slight deviation from this trend (typical of a flat empty channel) because of the inertial effects induced by the spacer. The CFD results are in fair agreement with the experimental data; the deviation is of either sign and is maximum ( 14\%) for the geometry D0 and pure water as the working fluid. The discrepancy may be due to several factors, including the irregularities in the real spacer, which of course cannot be taken into account in the numerical simulations.

Also, the same figure (Fig. 8) shows that the D0 spacer, being thinner than the F45 one, exhibited higher pressure drops at any given flow rate.

In Fig. 9 the Fanning friction factor $(f)$ is reported as a function of the Reynolds number $(R e)$ for the same cases of Fig. 8. These quantities were calculated with velocity and characteristic size relevant to the empty channel:

$$
\operatorname{Re}=\frac{\rho w_{\text {mean }, \text { void }} d_{h, \text { void }}}{\mu}
$$

and

$$
f=\frac{\Delta p}{\Delta z} \frac{d_{h, \text { void }}}{2 \rho w_{\text {mean,void }}^{2}}
$$

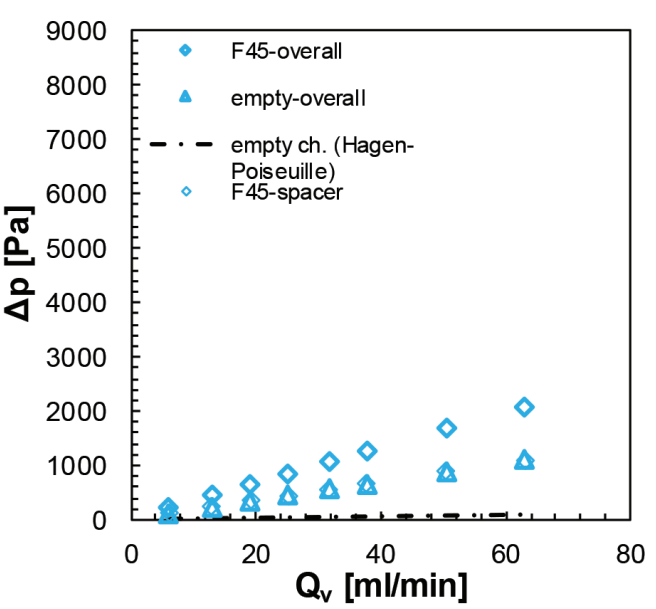

Fig. 7. Experimental measurements for the D0 (left) and F45 (right) spacers. The charts report also the distributed pressure drop in empty channels with the same thicknesses. 


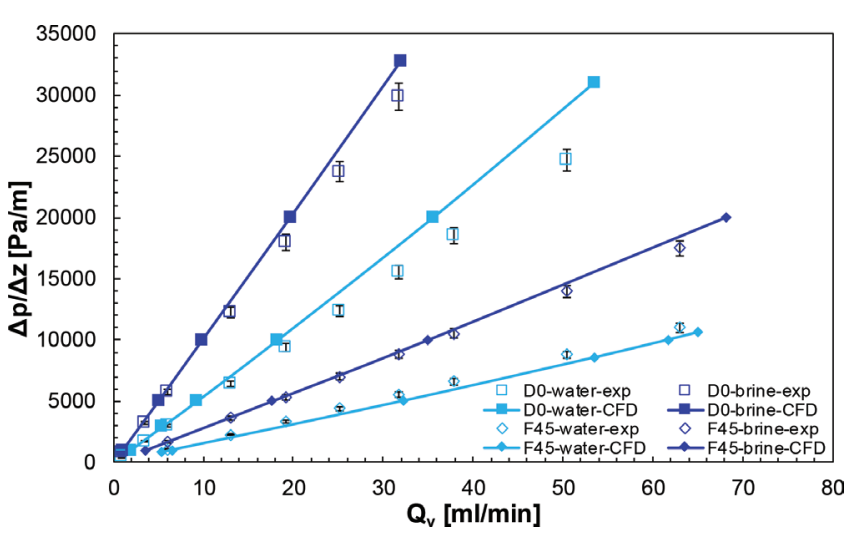

Fig. 8. Distributed pressure drop as a function of the flow rate in a channel $10 \mathrm{~cm}$ wide for D0 and F45 spacer-filled channels: comparison between CFD and experiments. Each experimental datum is the mean value between two different measurements: relevant error bars refer to the maximum deviation found during the experimental campaign (i.e. $7 \%$ between the same two experiments).

where $w_{\text {mean, void }}$ is the average velocity along the main flow direction $z$ in the corresponding empty (spacer-less) channel (superficial velocity), $d_{h, \text { void }}$ is the hydraulic diameter of an empty channel of infinite streamwise and spanwise extent

$d_{h, \text { void }}=2 h$

and $\Delta p / \Delta z$ is the mean pressure gradient along the main flow direction and coincides with $K_{p}$ of Eq. (4).

The $f$-Re curves can be approximated by power laws as

$$
f=A R e^{n}
$$

As it can be seen in Fig. 9, $f$ has trend proportional to $R e^{-1}$ at the lowest Re numbers, where a creeping self-similar flow occurs; in these conditions, the inertial forces are neg-

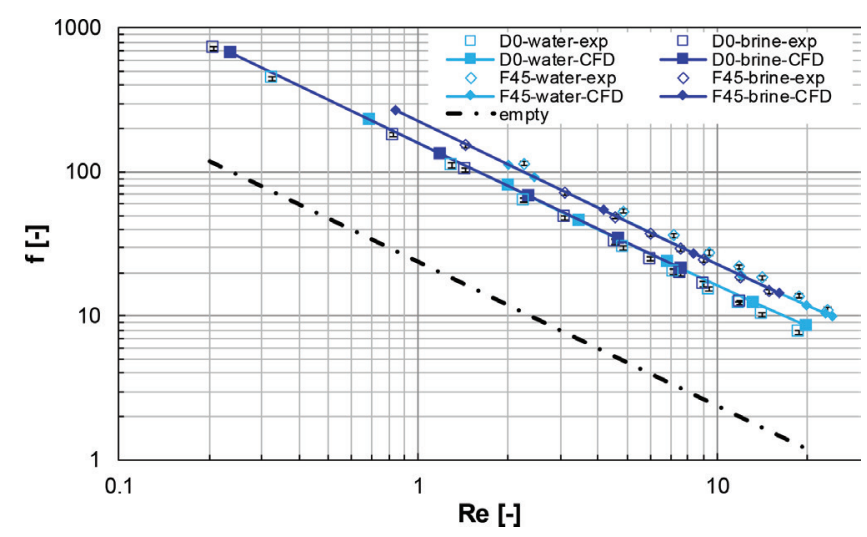

Fig. 9. Fanning friction factor as a function of Reynolds number for D0 and F45 spacer-filled channels: comparison between CFD and experiments. ligible compared to the viscous ones (creeping or Stokes flow), and the normalized flow field remains the same as the velocity increases (self-similar flow). Differently, values of $n$ slightly deviating from -1 can be observed as $R e$ increases, because the spacer induces growing inertial effects consisting of increasing convective motions perpendicular to the main flow direction thus leading the flow field to lose its self-similarity.

The insertion of a spacer causes friction factors to significantly increase with respect to the empty channel: in the range of $R e$ investigated here, the relative increment ranges from 6.64 to 7.13 times for the D0 spacer and from 9.43 to 10.47 times for the F45 spacer. In dimensionless terms, the geometries of the two net spacers investigated are similar; in fact, the pitch-to-height ratio is 2.89 for the D0 spacer and 2.42 for the F45 spacer (Table 3 ). The higher $f$ values exhibited by the F45 spacer-filled channel can be attributed just to the effect of its lower relative mesh spacing, as at low $R e$ numbers the flow attack angle was proved to not affect pressure drop [19]. Of course, the fluid properties must have no effect on the $f$-Re trend, as shown by the CFD simulations; however, in the cases of experimental data some slight discrepancies can be observed.

The following Figs. 10 and 11 illustrate by means of 2-D and 3-D streamlines the main features of the velocity distribution in the geometries examined, and are just an example of the complete access to a complex, three-dimensional flow field made possible by CFD in conjunction with advanced graphic capabilities. In general, local information on flow field provided by CFD models allows to easily understand why a geometrical configuration could be more energetically efficient (in terms of pressure drop reduction) than another. Moreover, although the attention of the present study is focused on the purely hydrodynamic aspects, it is clear that the velocity distributions are also indicative of the mass transfer enhancement expected by a given mixing promoter.

Fig. 10 shows 2D streamlines along with contours of the normalized modulus of the velocity (i.e. ) $u_{\text {norm }}|u| / w_{\text {ave }}$ on three different $y-z$ planes. In Fig. 11, 3D streamlines are represented in different colours depending on the area from which they start. The intensity of the colours indicates the normalized modulus of the velocity. The presence of the spacer strongly affects the flow field: the streamlines are not rectilinear and parallel (1D), as in the case of the empty channel, but the fluid threads follow complex 3D flow paths with additional vertical and lateral motions induced by the wires (Fig. 11). Moreover, a local increase of velocity occurs where the obstacles reduce the passage section (Figs. 10, 11).

As Re increases, non self-similar flow fields are obtained, due to the convective motions that take place with an increasing relative intensity of the velocity components perpendicular to the main flow direction. The increase of these convective motions at higher $R e$ can be inferred from Fig. 10, where at $R e=20$ the flow field loses its symmetry (typical of creeping flows) with respect to $R e=2$.

In the D0 spacer-filled channel, a series of filaments is parallel to the main flow direction. In this case, the additional convective motions are determined by the transverse filaments, while dead zones, where the fluid moves slowly, are observable near the longitudinal wires (Figs. 10, 11). 


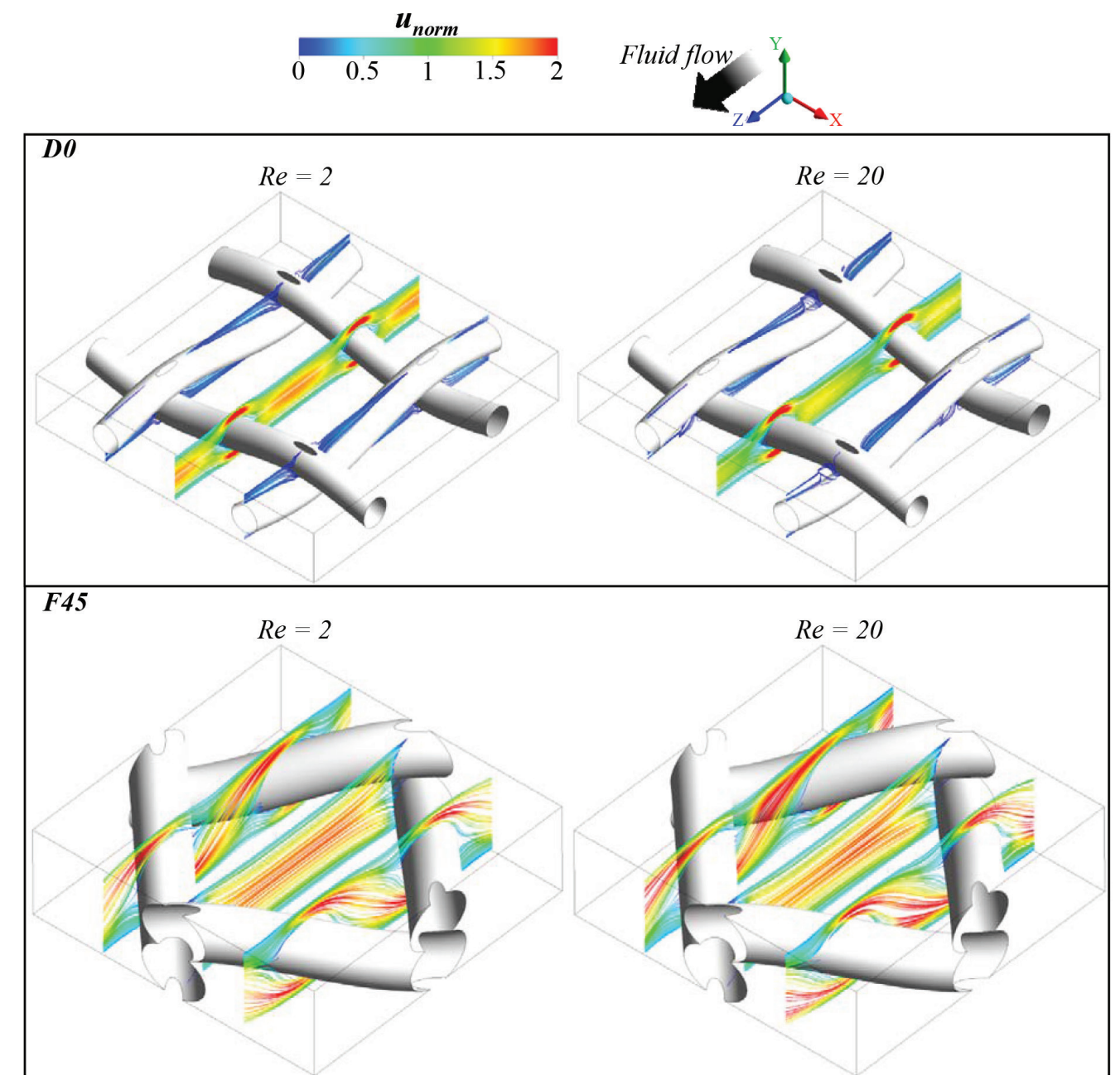

Fig. 10. 2D streamlines on $y$-z planes in D0 and F45 spacer-filled channels at Reynolds number 2 and 20.

In the F45 spacer-filled channel, the spacer orientation is such that the main flow direction bisects the angle between the filaments. This configuration generates a very different flow field, characterized by more tortuous flow paths and by the absence of dead zones (Fig. 11).

\section{Conclusions}

Pressure drops distributed along different spacer-filled channels were predicted by CFD simulations. Experimental pressure drops measurements in a flow cell at lab-scale and provided with the same spacers were carried out for validating the CFD simulations. In particular, a novel procedure is proposed to experimentally infer the pressure drop in the channel from the overall one along the whole flow cell. Spacers made by woven wires $\left(\right.$ at $90^{\circ}$ ) were investigated. Experimental results showed that the pressure drops in the manifolds were $~ 50-70 \%$ of the overall loss through the flow cell, confirming data from the literature on conventional stacks with cylindrical ducts as manifolds. In this regard, a distribution system designed with rectangular geometry was shown to be very effective to dramatically reduce the pressure loss occurring in the manifolds [48].
A good agreement between CFD results and experimental data was found, so that CFD is proved to be a cost effective tool for the prediction of the fluid dynamics within spacer-filled channels. Results show that the adoption of a spacer led the pressure drop to increase up to 10 times that relevant to the spacer-less channel. Therefore, the choice of the spacer can have a decisive impact on the performance of a RED stack, and the proper attention must be devoted to the design and optimization of the channel geometry.

CFD simulations showed that the flow field in the channel is significantly different from the case of the empty channel. Although the regime is steady (low Re numbers are typical for RED channels), the flow field is characterized by convective motions perpendicular to the main flow direction due to the spacer filaments. At very low Re numbers, creeping flows take place; as $R e$ increases, the relative intensity of the velocity components perpendicular to the main flow direction increases, and the fluid flow loses the self-similarity feature. When the spacer has a series of filaments parallel to the main flow direction and the other series perpendicular, the additional (with respect to an empty channel) convective motions are induced by the transverse filaments, and low velocity zones are generated in the prox- 


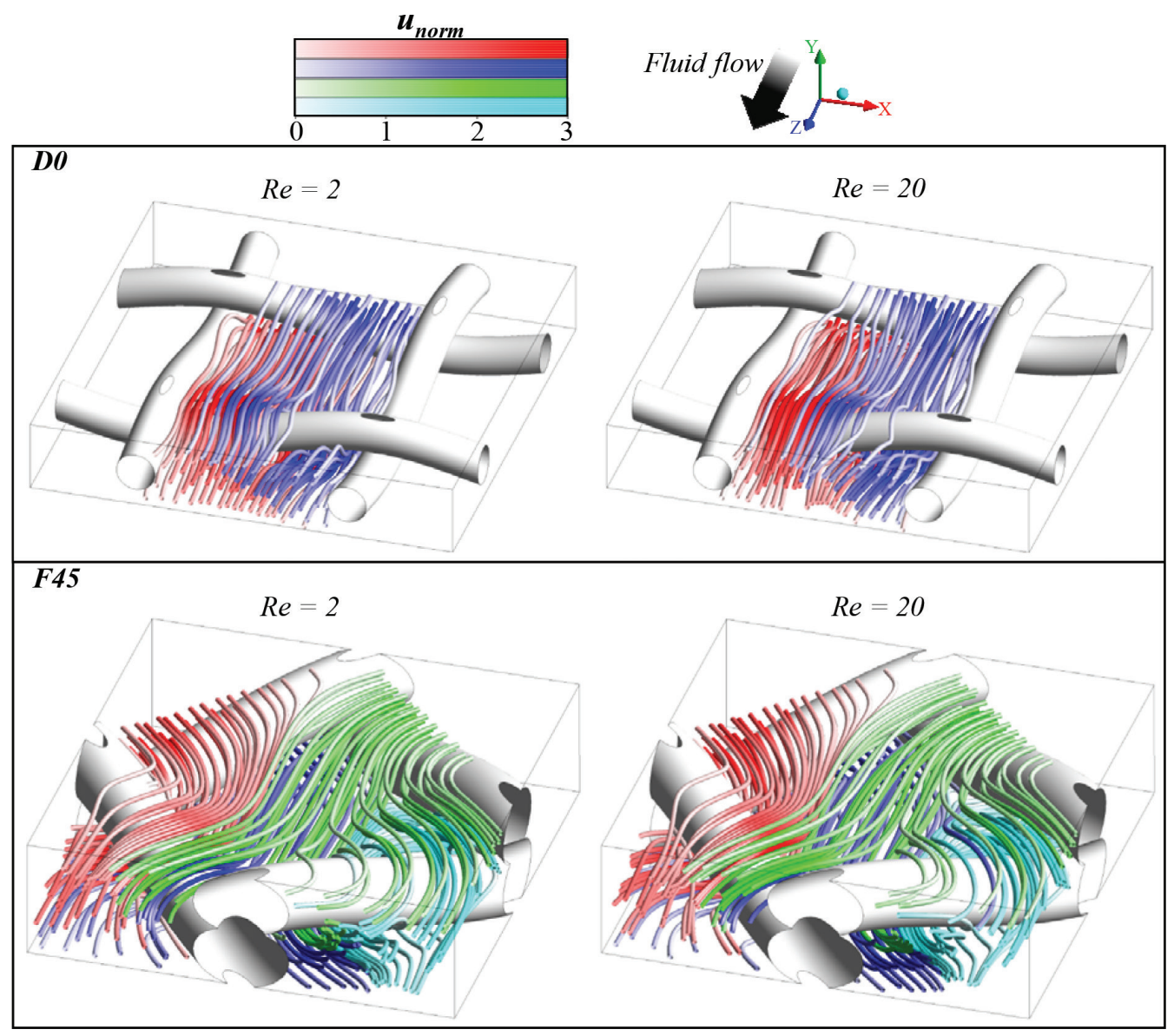

Fig. 11. 3D streamlines in D0 and F45 spacer-filled channels at Reynolds number 2 and 20.

imity of the longitudinal wires. Conversely, when the flow attack angle is $45^{\circ}$ with respect to the filaments, the flow field is more complex, exhibiting more tortuous trajectories without calm regions. Thus, this orientation of the spacer is more promising for improving mixing in a RED channel.

\section{Acknowledgements}

This work has been performed within the REAPower (Reverse Electrodialysis Alternative Power production) project, funded by the EU-FP7 programme (Project Number: 256736), http:/ / www.reapower.eu.

\section{Notations}

$\Delta p \quad-$ Pressure drop $[\mathrm{Pa}]$

$\Delta p_{\text {empty }}$ - Pressure drop in the flow cell with empty channel [Pa]

$\Delta p_{H P} \quad$ - Pressure drop in a spacer-less channel of infinite spanwise and streamwise extent (calculated by the Hagen-Poiseuille formula) [Pa]

$\Delta p_{\text {over }} \quad$ - Overall pressure drop in the flow cell with spacer-filled channel [Pa]
$\Delta p_{\text {spacer }} \quad$ - Pressure drop in the spacer-filled channel [Pa]

$A^{\text {spacer }}-$ Coefficient in the equation for $f$ as a function of $\operatorname{Re}$ [-]

$d_{h, \text { void }} \quad-$ Hydraulic diameter of the spacer-less channel [m]

$f \quad-$ Fanning friction factor $[-]$

$g \quad-$ Gravitational acceleration $\left[\mathrm{m} \mathrm{s}^{-2}\right]$

$\mathrm{H}_{\text {transducer }}$ - Height of the pressure transducer [m]

$H_{\text {outlet section }}$ - Height of the outlet section in the flask [m]

$h^{\text {outlet section }}$ - Channel thickness [m]

$K_{p} \quad$ - Pressure gradient along the main flow direction $\left[\mathrm{N} \mathrm{m}^{-3}\right]$

$\vec{k} \quad$ - Unit vector of the $z$ axis $[-]$

L $\quad-$ Channel width [m]

$n \quad$ - Exponent to Re in the equation for $f[-]$

$\tilde{p} \quad-$ Periodic component of pressure [Pa]

$p_{\text {tranducer }}-$ Pressure measured by the transducer $[\mathrm{Pa}]$

$Q_{v}-$ Volume flow rate $\left[\mathrm{m}^{3} \mathrm{~s}^{-1}\right]$

Re - Reynolds number [-]

$\vec{u} \quad-$ Velocity of solution $\left[\mathrm{m} \mathrm{s}^{-1}\right]$

$u_{\text {norm }}-$ Normalized velocity, $|\vec{u}| / w_{\text {ave }}[-]$

$t \quad-$ Time [s]

$w \quad-$ Velocity component along $z\left[\mathrm{~m} \mathrm{~s}^{-1}\right]$

$w_{\text {ave }} \quad-$ Average velocity along $z$ in the unit cell $\left[\mathrm{m} \mathrm{s}^{-1}\right]$ 
$w_{\text {mean, void }}-$ Average velocity along $z$ in a corresponding spacer less channel $\left[\mathrm{m} \mathrm{s}^{-1}\right]$

$x \quad$ - Cartesian position coordinate $[\mathrm{m}]$

$y \quad$ - Cartesian position coordinate $[\mathrm{m}]$

$z \quad-$ Cartesian position coordinate along the main flow direction $[\mathrm{m}]$

\section{Greek letters}

$\mu \quad-$ Dynamic viscosity of solution [Pa s]

$v \quad-$ Cinematic viscosity of solution $\left[\mathrm{m}^{2} \mathrm{~s}^{-1}\right]$

$\rho \quad-$ Solution density $\left[\mathrm{kg} \mathrm{m}^{-3}\right]$

\section{Abbreviations}

CFD - Computational Fluid Dynamics

RED - Reverse ElectroDialysis

\section{References}

[1] M. Bevacqua, A. Carubia, A. Cipollina, A. Tamburini, M. Tedesco, G. Micale, Performance of a RED system with Ammonium Hydrogen Carbonate solutions, Desal. Water Treat., 57 (2016) 23007-23018.

[2] Y. Kim, W.S. Walker, D.F. Lawler, Electrodialysis with spacers: Effects of variation and correlation of boundary layer thickness, Desalination, 274 (2011) 54-63.

[3] S.S. Sablani, M.F.A. Goosen, R. Al-Belushi, M. Wilf, Concentration polarization in ultrafiltration and reverse osmosis: a critical review, Desalination, 141 (2001) 269-289.

[4] A. Tamburini, A. Cipollina, S. Al-Sharif, M. Albeirrutty, L. Gurreri, G. Micale, M. Ciofalo, Assessment of temperature polarization in membrane distillation channels by liquid crystal thermography, Desal. Water Treat., 55 (2015) 2747-2765.

[5] Y. Tanaka, Pressure distribution, hydrodynamics, mass transport and solution leakage in an ion-exchange membrane electrodialyzer, J. Membr. Sci., 234 (2004) 23-39.

[6] D.A. Vermaas, E. Guler, M. Saakes, K. Nijmeijer, Theoretical power density from salinity gradients using reverse electrodialysis, Energy Procedia, 20 (2012) 170-184.

[7] D.A. Vermaas, M. Saakes, K. Nijmeijer, Doubled power density from salinity gradients at reduced intermembrane distance, Environ. Sci. Technol., 45 (2011) 7089-7095.

[8] A. Cipollina, G. Micale, Sustainable Energy from Salinity Gradients, section 6.6, page 209, 1st ed., Woodhead Publishing, Amsterdam, 2016.

[9] R.E. Pattle, Production of elctric power by mixing fresh and salt water in hydroelectric pile, Nature, 174 (1954) 660.

[10] J.W. Post, H.V.M. Hamelers, C.J.N. Buisman, Energy recovery from controlled mixing salt and fresh water with a reverse electrodialysis system, Environ. Sci. Technol., 42 (2008) 57855790 .

[11] J. Veerman, M. Saakes, S.J. Metz, G.J. Harmsen, Reverse electrodialysis: Performance of a stack with 50 cells on the mixing of sea and river water, J. Membr. Sci., 327 (2009) 136-144.

[12] A. Daniilidis, D.A. Vermaas, R. Herber, K. Nijmeijer, Experimentally obtainable energy from mixing river water, seawate or brines with reverse electrodialysis, Renew. Energy, 64 (2014) 123-131

[13] D.A. Vermaas, M. Saakes, K. Nijmeijer, Power generation using profiled membranes in reverse electrodialysis, J. Membr. Sci., 385-386 (2011) 234-242.

[14] D.A. Vermaas, M. Saakes, K. Nijmeijer, Enhanced mixing in the diffusive boundary layer for energy generation in reverse electrodialysis, J. Membr. Sci., 453 (2014) 312-319.

[15] M. Tedesco, A. Cipollina, A. Tamburini, I.D.L. Bogle, G. Micale, A simulation tool for analysis and design of Reverse Electrodialysis using concentrated brines, Chem. Eng. Res. Des., 93 (2015) 441-456.
[16] M. Tedesco, A. Cipollina, A. Tamburini, W. van Baak, G. Micale, Modelling the Reverse ElectroDialysis process with seawater and concentrated brines, Desal. Water Treat., 49 (2012) 404-424.

[17] J. Veerman, M. Saakes, S.J. Metz, G.J. Harmsen, Reverse electrodialysis: A validated process model for design and optimization, Chem. Eng. J., 166 (2011) 256-268.

[18] J. Veerman, M. Saakes, S.J. Metz, G.J. Harmsen, Electrical power from sea and river water by reverse electrodialysis: a first step from the laboratory to a real power plant, Environ. Sci. Technol., 44 (2010) 9207-9212.

[19] L. Gurreri, A. Tamburini, A. Cipollina, G. Micale, M. Ciofalo, CFD prediction of concentration polarization phenomena in spacer-filled channels for reverse electrodialysis, J. Membr. Sci., 468 (2014) 133-148.

[20] J. Jagur-Grodzinski, R. Kramer, Novel process for direct conversion of free energy of mixing into electric power, Ind. Eng. Chem. Process Des. Dev., 25 (1986) 443-449.

[21] M. Tedesco, C. Scalici, D. Vaccari, A. Cipollina, A. Tamburini, $\mathrm{G}$. Micale, Performance of the first reverse electrodialysis pilot plant for power production from saline waters and concentrated brines, J. Membr. Sci., 500 (2016) 33-35.

[22] P. Długołęcki, A. Gambier, K. Nijmeijer, M. M. Wessling, Practical potential of reverse electrodialysis as process for sustainable energy generation, Environ. Sci. Technol., 43 (2009) 6888-6894.

[23] S. Pawlowski, P. Sistat, J.G. Crespo, S. Velizarov, Mass transfer in reverse electrodialysis: Flow entrance effects and diffusion boundary layer thickness, J. Membr. Sci., 471 (2014) 72-83.

[24] S. Pawlowski, J.G. Crespo, S. Velizarov, Pressure drop in reverse electrodialysis: Experimental and modeling studies for stacks with variable number of cell pairs, J. Membr. Sci., 462 (2014) 96-111.

[25] M.H. Dirkse, W.K.P. van Loon, J.W. Post, J. Veerman, J.D. Stigter, G.P.A. Bot, Extending potential flow modelling of flatsheet geometries as applied in membrane-based systems, J. Membr. Sci., 325 (2008) 537-545.

[26] R. Ghidossi, D. Veyret, P. Moulin, Computational fluid dynamics applied to membranes: State of the art and opportunities, Chem. Eng. Process., 45 (2006) 437-454.

[27] G.A. Fimbres-Weihs, D.F. Fletcher, Review of 3D CFD modeling of flow and mass transfer in narrow spacer-filled channels in membrane modules, Chem. Eng. Process., 49 (2010) 759-781.

[28] J. Schwinge, D.E. Wiley, D.F. Fletcher, Simulation of the flow around spacer filaments between channel walls. 1. Hydrodynamics, Ind. Eng. Chem. Res., 41 (2002) 2977-2987.

[29] S.K. Karode, A. Kumar, Flow visualization through spacer filled channels by computational fluid dynamics I. Pressure drop and shear rate calculations for flat sheet geometry, J. Membr. Sci., 193 (2001) 69-84.

[30] C.P. Koutsou, S.G. Yiantsios, A.J. Karabelas, Direct numerical simulation of flow in spacer-filled channels: Effect of spacer geometrical characteristics, J. Membr. Sci., 291 (2007) 53-69.

[31] F. Li, W. Meindersma, A.B. de Haan, T. Reith, Optimization of commercial net spacers in spiral wound membrane modules, J. Membr. Sci., 208 (2002) 289-302.

[32] S.M. Mojab, A. Pollard, J.G. Pharoah, S.B. Beale, E.S. Hanff, Unsteady laminar to turbulent flow in a spacer-filled channel, Flow Turbul. Combust., 92 (2014) 563-577.

[33] V.V. Ranade, A. Kumar, Fluid dynamics of spacer filled rectangular and curvilinear channels, J. Membr. Sci., 271 (2006) 1-15.

[34] L.C. Santos, V. Geraldes, S. Velizarov, J.G. Crespo, Investigation of flow patterns and mass transfer in membrane module channels filled with flow-aligned spacers using computational fluid dynamics (CFD), J. Membr. Sci., 305 (2007) 103-117.

[35] M. Shakaib, S.M.F. Hasani, M. Mahmood, Study on the effects of spacer geometry in membrane feed channels using threedimensional computational flow modeling, J. Membr. Sci., 297 (2007) 74-89.

[36] D. Dendukuri, S.K. Karode, A. Kumar, Flow visualization through spacer filled channels by computational fluid dynamics-II: Improved feed spacer designs, J. Membr. Sci., 249 (2005) $41-49$. 
[37] F. Li, W. Meindersma, A.B. de Haan, T. Reith, Novel spacers for mass transfer enhancement in membrane separations, J. Membr. Sci., 253 (2005) 1-12.

[38] P. Xie, L.C. Murdoch, D.A. Ladner, Hydrodynamics of sinusoidal spacers for improved reverse osmosis performance, J. Membr. Sci., 453 (2014) 92-99.

[39] L. Gurreri, A. Tamburini, A. Cipollina, G. Micale, M. Ciofalo, Flow and mass transfer in spacer-filled channels for reverse electrodialysis: a CFD parametrical study, J. Membr. Sci., 497 (2016) 300-317.

[40] L. Gurreri, M. Ciofalo, A. Cipollina, A. Tamburini, W. van Baak, G. Micale, CFD modelling of profiled-membrane channels for Reverse Electrodialysis, Desalin. Water Treat., 55 (2015) 3404-3423.

[41] A. Tamburini, G. La Barbera, A. Cipollina, M. Ciofalo, G. Micale, CFD simulation of channels for direct and reverse electrodialysis, Desalin. Water Treat., 48 (2012) 370-389.

[42] A. Tamburini, G. La Barbera, A. Cipollina, G. Micale, M. Ciofalo, CFD prediction of scalar transport in thin channels for reverse electrodialysis, Desalin. Water Treat., 55 (2015) 3424-3445.

[43] S. Pawlowski, V. Geraldes, J.G. Crespo, S. Velizarov, Computational fluid dynamics (CFD) assisted analysis of profiled membranes performance in reverse electrodialysis, J. Membr. Sci. 502 (2016) 179-190.

[44] D.W. Green, R.H. Perry, Perry's Chemical Engineers' Handbook, eighth ed., McGraw-Hill, New York, 2007.

[45] H. Ozbek, J.A. Fair, S.L. Phillips, Viscosity of aqueous sodium chloride solutions from $0-150^{\circ} \mathrm{C}$, University of California, Berkeley, 2010

[46] V.V. Ranade, A. Kumar, Comparison of flow structures in spacer-filled flat and annular channels, Desalination, 191 (2006) 236-244.
[47] M. Shakaib, S.M.F. Hasani, M. Mahmood, CFD modeling for flow and mass transfer in spacer-obstructed membrane feed channels, J. Membr. Sci., 326 (2009) 270-284.

[48] L. Gurreri, A. Tamburini, A. Cipollina, G. Micale, CFD analysis of the fluid flow behavior in a reverse electrodialysis stack, Desal. Water Treat., 48 (2012) 390-403.

[49] C.P. Koutsou, S.G. Yiantsios, A.J. Karabelas, A numerical and experimental study of mass transfer in spacer-filled channels: Effects of spacer geometrical characteristics and Schmidt number, J. Membr. Sci., 326 (2009) 234-251.

[50] Y.L. Li, K.L. Tung, CFD simulation of fluid flow through spacer-filled membrane module: selecting suitable cell types for periodic boundary conditions, Desalination, 233 (2008) 351-358.

[51] E. Lauga, M.P. Brenner, H.A. Stone, Microfluidics: The No-Slip Boundary Condition, Chapter 15, in: J. Foss, C. Tropea, A. Yarin (Eds.) Handbook of Experimental Fluid Dynamics, Springer, New York, 2005.

[52] Ansys Inc., Ansys-CFX Reference Guide, Release 14.5, 2012.

53] S.V. Patankar, Numerical Heat Transfer and Fluid Flow, Hemisphere Publishing Corp., 1980.

[54] C.M. Rhie, W.L. Chow, Numerical study of the turbulent flow past an airfoil with trailing edge separation, AIAA Journal, 21 (1983) 1525-1532.

[55] B.R. Hutchinson, G.D. Raithby, A multigrid method based on the Additive Correction strategy, Numer. Heat Transfer, 9 (1986) 511-537.

[56] T.J. Barth, D.C. Jespersen, The design and application of upwind schemes on unstructured meshes, in: 27th AIAA Aerospace Sciences Meeting and Exhibit, Reno, NV, USA, 1989. 